\title{
A rare case of low-grade appendiceal mucinous neoplasm within an incarcerated Amyand's hernia
}

\author{
Diana Fernandes, Maria Olim Sousa, Ricardo Viveiros, Sara Silva, \\ Susana Nóbrega, Laurentina Silva
}

\begin{abstract}
Introduction: We report a rare case of lowgrade appendiceal mucinous neoplasm (LAMN) within an incarcerated Amyand's hernia. Case Report: The patient was admitted for an elective surgery due to an asymptomatic rightsided inguinal hernia. The operative findings were suggestive of an appendiceal mucocele. Appendectomy and herniorrhaphy were performed. The histology report revealed a lowgrade appendiceal mucinous neoplasm. The patient had no clinical, biochemical or imaging signs of disease or hernia recurrence two years postoperatively. Conclusion: Surgical treatment involves appendectomy and hernia repair, which is performed without the implantation of synthetic mesh. The possibility of finding an incidental neoplasm should be considered during the surgery of an Amyand's hernia.
\end{abstract}

Keywords: Amyand's hernia, Appendectomy, Appendix, Inguinal hernia, Low-grade appendiceal mucinous neoplasm (LAMN), Mucocele

Diana Fernandes ${ }^{1}$, Maria Olim Sousa ${ }^{1}$, Ricardo Viveiros ${ }^{1}$, Sara Silva ${ }^{1}$, Susana Nóbrega ${ }^{2}$, Laurentina Silva ${ }^{2}$

Affiliations: ${ }^{1} \mathrm{MD}$, General Surgery Resident, General Surgery Department, Funchal Central Hospital, SESARAM, E.P.E., Funchal, Madeira, Portugal; ${ }^{2} \mathrm{MD}$, General Surgery Specialist, General Surgery Department, Funchal Central Hospital, SESARAM, E.P.E., Funchal, Madeira, Portugal.

Corresponding Author: Diana Fernandes, Avenida Luís de Camões n. 57, Funchal, Madeira, Portugal, 9004-514; Email: dianarfernandes@gmail.com

Received: 21 February 2017

Accepted: 11 March 2017

Published: 04 April 2017

\section{How to cite this article}

Fernandes D, Sousa MO, Viveiros R, Silva S, Nóbrega S, Silva L. A rare case of low-grade appendiceal mucinous neoplasm within an incarcerated Amyand's hernia. Case Rep Int 2017;6:13-16.

Article ID: 100035CRINTDF2017

$* * * * * * * * *$

doi:10.5348/crint-2017-35-CR-4

\section{INTRODUCTION}

Amyand's hernia is a rare form of an inguinal hernia in which the vermiform appendix is located within the hernia sac. It is seen in less than $1 \%$ of inguinal hernias. According to Losanoff and Basson, Amyand's hernias can be classified into four subtypes, based on the status of the appendix [1].

Low-grade appendiceal mucinous neoplasm (LAMN) is a rare entity with an estimated incidence ranging from $0.2-0.7 \%$ of all excised appendixes [2]. Approximately $25-50 \%$ of LAMN are incidental findings during imaging studies, endoscopic examinations or during surgery [3].

The initial presentation can range from asymptomatic to abdominal pain or a palpable abdominal mass. The differential diagnosis may include acute appendicitis, cecal mass, diverticulitis, lymphoma, peritoneal carcinomatosis or sarcomatosis, mesothelioma, pseudomyxoma peritonei, retroperitoneal cyst, or in females, ovarian tumors $[2,4,5]$.

Its clinical importance resides in the fact that rupture of the appendix and spillage of mucinous contents into the peritoneal cavity can develop a pseudomyxoma peritonei [6]. 


\section{CASE REPORT}

A 76-year-old male patient was admitted for an elective surgery due to an asymptomatic right-sided inguinal hernia. During dissection of the hernia sac, an inflamed and dilated appendix was discovered. Based on the experience of the surgeons a mucocele of the appendix was suspected. Rupture of the appendix occurred during manipulation outside of the abdominal cavity and mucinous contents were seen inside the appendix (Figures 1-3).

Under rigorous protection of surgical borders an appendectomy was performed and the hernia was repaired without prosthetic material after cleaning the surgical field. The postoperative period was uneventful and the patient was discharged after $24 \mathrm{~h}$ of surgery.

The histology report revealed a low-grade appendiceal mucinous neoplasm. The patient had no clinical, biochemical or imaging signs of disease or hernia recurrence after two years of follow-up.

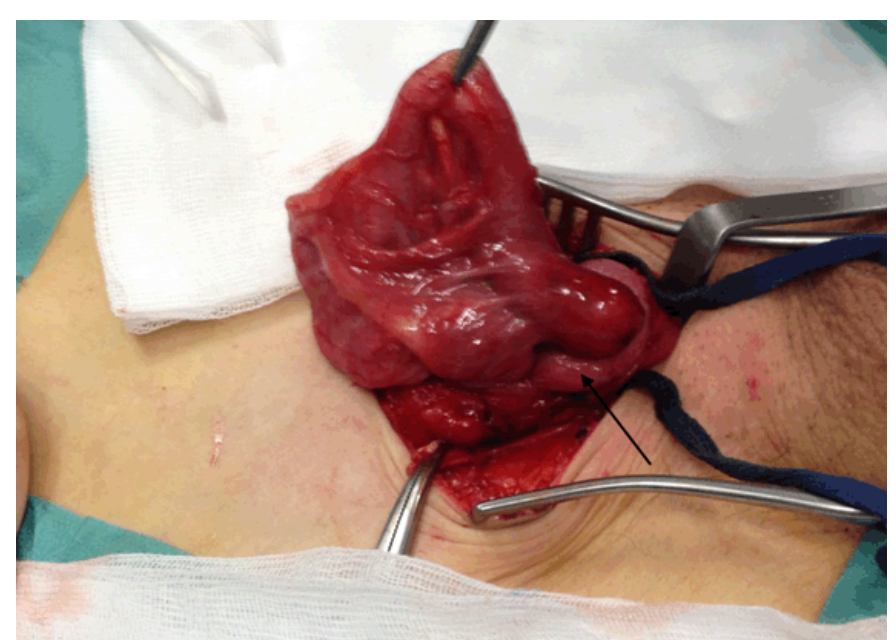

Figure 1: The vermiform appendix inside the encarcerated Amyand's hernia (arrow showing the hernia sac).

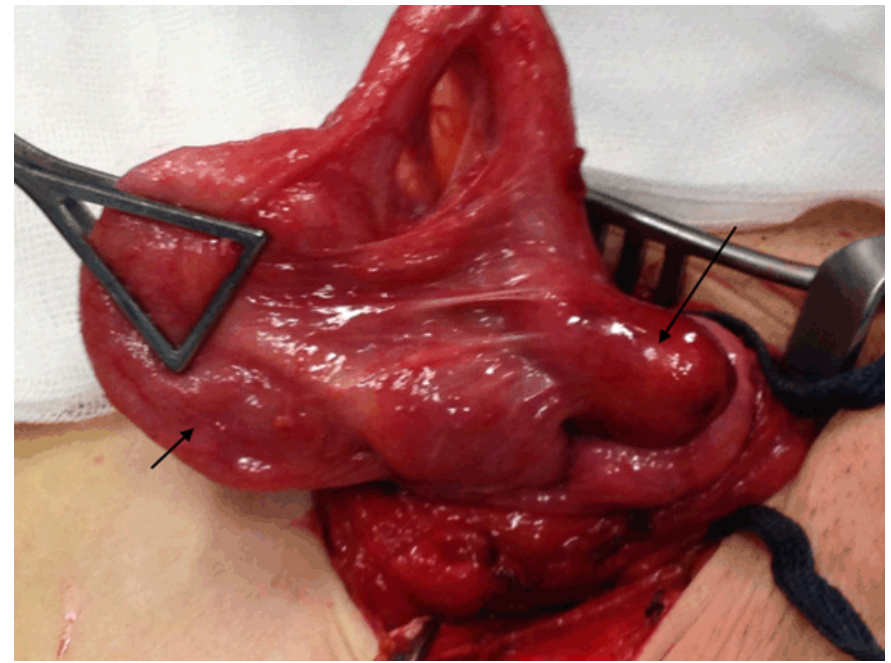

Figure 2: An inflamed and dilated appendix suspected of mucocele (short arrow showing the cecum; long arrow showing the appendix).

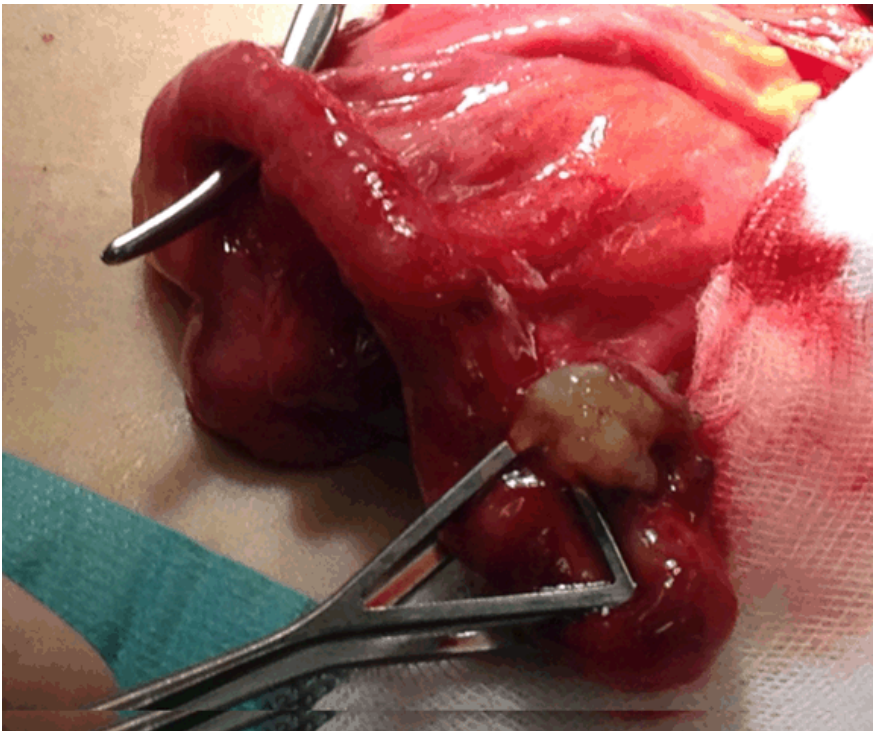

Figure 3: The mucinous contents inside the appendix after rupture.

\section{DISCUSSION}

Claudius Amyand was a French surgeon who performed the first successful appendectomy in 1735, on an 11-year-old boy who presented with an inflamed, perforated appendix in his inguinal hernia sac.

Amyand's hernia is considered rare. Among all cases of incarcerated right inguinal hernias, their prevalence is estimated to be around $1 \%$ and most cases are diagnosed intraoperatively. Men are affected more commonly but they occur in patients of all ages, from babies to elderly patients [7-9].

It almost exclusively occurs on the right side, mostly due to the normal anatomical position of the appendix, although there have been reports of left-sided Amyand's hernia. In such cases, there are usually an associated intestinal malrotation, situs inversus or a mobile cecum [10].

Losanoff and Basson have proposed a classification and staging system for Amyand's hernia into the following four subtypes, based on the status of the appendix:

- normal appearing appendix in the inguinal sac

- inflamed appendix

- perforation of the appendix

- complicating intra-abdominal pathology (e.g. abscess or malignancy) [1]

Amyand's hernia is clinically difficult to identify and the preoperative diagnosis is very uncommon. Weber et al., in a review of 60 cases over a 12-year period, only diagnosed one case preoperatively [11].

The treatment of Amyand's hernia depends on the inflammatory state of the appendix. Many authors suggest that prophylactic appendectomy is only necessary when the appendix is found with signs of inflammation $[12,13]$. Other authors suggest that all patients should have an appendectomy because the appendix could 
reherniate or cause appendicitis, especially in younger patients [14].

Some cases have been reported of an Amyand's hernia with a coexistent malignancy of the appendix. This may be due to the rarity of appendix neoplasms, which are found in only $1 \%$ of cases $[15,16]$. Mucinous neoplasms of the appendix occur much less frequently. The 2010 WHO classification distinguishes three categories of mucinous neoplasms mucinous adenoma, LAMN and appendiceal adenocarcinoma [17]. Low-grade appendiceal mucinous neoplasm is considered a low-grade well-differentiated adenoma that can proliferate outside the appendix in a malignant way [18].

Clinical diagnosis of mucinous neoplasms is usually difficult. Approximately, half of the cases are asymptomatic and detected incidentally. Symptomatic tumors can present with abdominal pain or mass, weight loss, nausea and vomiting or acute appendicitis [19].

When presenting as a mucocele, their rupture may result in the feared complication of pseudomyxoma peritonei due to gradual intraperitoneal accumulation of mucin. The majority of these tumors are discovered incidentally since their clinical evolution is usually silent [20].

On literature search there are no previously published reports of a low-grade appendiceal mucinous neoplasm presenting as the lead point for an Amyand's hernia, making this case unique.

\section{CONCLUSION}

We report a rare case of a patient with a LAMN incarcerated within an Amyand's hernia. Surgical treatment involves appendectomy and hernia repair, which is performed without the implantation of synthetic mesh due to the contaminated operating field. If a mucocele is suspected care should be taken to avoid spillage of mucous contents inside the peritoneal cavity. During surgery for an Amyand's hernia, the possibility of finding an incidental neoplasm should be considered.

$* * * * * * * *$

\section{Author Contributions}

Diana Fernandes - Substantial contributions to conception and design, Acquisition of data, Analysis and interpretation of data, Drafting the article, Revising it critically for important intellectual content, Final approval of the version to be published

Maria Olim Sousa - Substantial contributions to conception and design, Analysis and interpretation of data, Revising it critically for important intellectual content, Final approval of the version to be published Ricardo Viveiros - Substantial contributions to conception and design, Analysis and interpretation of data, Revising it critically for important intellectual content, Final approval of the version to be published
Sara Silva - Substantial contributions to conception and design, Analysis and interpretation of data, Revising it critically for important intellectual content, Final approval of the version to be published

Susana Nóbrega - Substantial contributions to conception and design, Revising it critically for important intellectual content, Final approval of the version to be published Laurentina Silva - Substantial contributions to conception and design, Revising it critically for important intellectual content, Final approval of the version to be published

\section{Guarantor}

The corresponding author is the guarantor of submission.

\section{Conflict of Interest}

Authors declare no conflict of interest.

\section{Copyright}

(C) 2017 Diana Fernandes et al. This article is distributed under the terms of Creative Commons Attribution License which permits unrestricted use, distribution and reproduction in any medium provided the original author(s) and original publisher are properly credited. Please see the copyright policy on the journal website for more information.

\section{REFERENCES}

1. Losanoff JE, Basson MD. Amyand hernia: A classification to improve management. Hernia 2008 Jun;12(3):325-6.

2. Chua TC, Moran BJ, Sugarbaker PH, et al. Earlyand long-term outcome data of patients with pseudomyxoma peritonei from appendiceal origin treated by a strategy of cytoreductive surgery and hyperthermic intraperitoneal chemotherapy. J Clin Oncol 2012 Jul 10;30(20):2449-56.

3. Rojnoveanu G, Ghidirim G, Mishin I, Vozian M, Mishina A. Preoperatively diagnosed mucocele of the appendix. Chirurgia (Bucur) 2014 MayJun;109(3):416-20.

4. Sugarbaker PH. Surgical responsibilities in the management of peritoneal carcinomatosis. J Surg Oncol 2010 Jun 15;101(8):713-24.

5. Zagrodnik DF II, Rose DM. Mucinous cystadenoma of the appendix: Diagnosis, surgical management, and follow-up. Curr Surg 2003 May-Jun;60(3):341-3.

6. Lee J, Gardiner KR, Wilson BG. Incidental mucinous cystadenocarcinoma of the appendix. Postgrad Med J 1996 Jan;72(843):55-6.

7. Phillips BJ, Perry CW. Appendiceal diverticulitis. Mayo Clin Proc 1999 Sep;74(9):890-2.

8. Schumpelick V, Dreuw B, Ophoff K, Prescher A. Appendix and cecum. Embryology, anatomy, and surgical applications. Surg Clin North Am 2000 Feb;80(1):295-318.

9. House MG, Goldin SB, Chen H. Perforated Amyand's hernia. South Med J 2001 May;94(5):496-8. 
10. Gupta S, Sharma R, Kaushik R. Left-sided Amyand's hernia. Singapore Med J 2005 Aug;46(8):424-5.

11. Weber RV, Hunt ZC, Kral JG. Amyand's hernia: Etiologic and therapeutic implications of two complications. Surg Rounds 1999;22:552-6.

12. Cankorkmaz L, Ozer H, Guney C, Atalar MH, Arslan MS, Koyluoglu G. Amyand's hernia in the children: A single center experience. Surgery 2010 Jan;147(1):140-3.

13. Okur MH, Karaçay S, Uygun I, Topçu K, Öztürk H. Amyand's hernias in childhood (a report on 21 patients): A single-centre experience. Pediatr Surg Int 2013 Jun;29(6):571-4.

14. Gurer A, Ozdogan M, Ozlem N, Yildirim A, Kulacoglu $\mathrm{H}$, Aydin R. Uncommon content in groin hernia sac. Hernia 2006 Apr;10(2):152-5.

15. Wu CL, Yu CC. Amyand's hernia with adenocarcinoid tumor. Hernia 2010 Aug;14(4):423-5.

16. Lee YT, Wu HS, Hung MC, Lin ST, Hwang YS, Huang MH. Ruptured appendiceal cystadenoma presenting as right inguinal hernia in a patient with left colon cancer: A case report and review of literature. BMC Gastroenterol 2006 Oct 30;6:32.

17. Carr NJ, McCarthy WF, Sobin LH. Epithelial noncarcinoid tumors and tumor-like lesions of the appendix. A clinicopathologic study of 184 patients with a multivariate analysis of prognostic factors. Cancer 1995 Feb 1;75(3):757-68.

18. Bosman FT, Carneiro F, Hruban RH, Theise ND. WHO Classification of tumours of the digestive system. vol 3. 4ed. Lyon, France: IARC Press; 2010. p. 122-5.

19. Dixit A, Robertson JH, Mudan SS, Akle C. Appendiceal mucocoeles and pseudomyxoma peritonei. World J Gastroenterol 2007 Apr 28;13(16):2381-4.

20. Athanassiou E, Spyridakis M, Karasavvidou F, et al. Low-Grade Appendiceal Mucinous Neoplasm Presenting as a Surgical Emergency: A Case Report. Case Rep Oncol 2009 Jan 21;2(1):7-11.
Access full text article on other devices

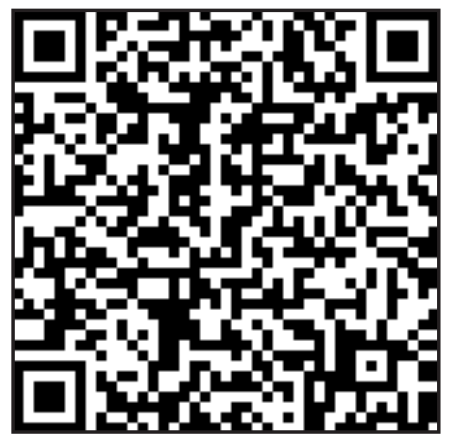

Access PDF of article on other devices

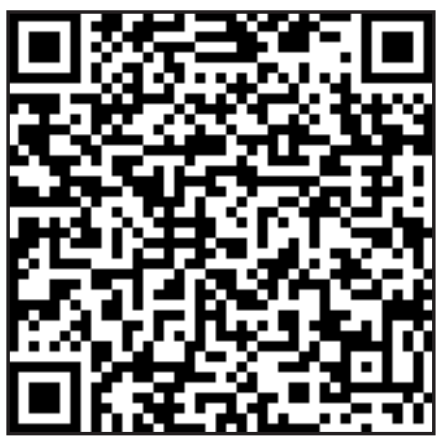

